\title{
Outdoor recreation and forest management: A plea for empirical data
}

\author{
by H.W. Harshaw ${ }^{1,2}$, S.R.J. Sheppard ${ }^{1}$ and R.A. Kozak ${ }^{3}$
}

\begin{abstract}
For many people, outdoor recreation provides one of the main opportunities to experience, interact with, and learn about forested landscapes. Yet public recreation use of forests in Canada is not yet well understood; knowing more about this important forest stakeholder group would help to address aspects of social sustainability in forest management. Four considerations for explicitly addressing outdoor recreation interests in forest land-use planning and for the collection of recreation data are presented: (1) normative; (2) pragmatic; (3) economic; and (4) governance. Approaches for the collection of recreation-use characteristics are also discussed.
\end{abstract}

Key words: outdoor recreation, data collection, sustainable forest management, social values

\section{RÉSUMÉ}

Pour plusieurs personnes, les activités récréatives en plein air constituent l'une des principales opportunités de faire connaissance, d'interagir et d'acquérir des connaissances sur les écosystèmes forestiers. Bien que l'utilisation à des fins récréatives par le public des forêts du Canada ne soit pas un domaine bien compris, une connaissance plus approfondie de ce groupe d'intervenants importants en foresterie aiderait à faire face aux aspects de durabilité sociale en aménagement forestier. Quatre points permettant de faire face explicitement aux questions d'activités récréatives en plein air lors de la planification de l'utilisation du territoire forestier et pour la cueillette de données sur les activités récréatives sont présentés : (1) l'aspect normatif, (2) l'aspect pragmatique, (3) l'aspect économique et (4) l'aspect administratif. Les approches pour la cueillette de données sur les caractéristiques d'utilisation à des fins récréatives font également l'objet de discussion.

Mots clés : activités récréatives en plein air, cueillette de données, aménagement forestier durable, valeurs sociales

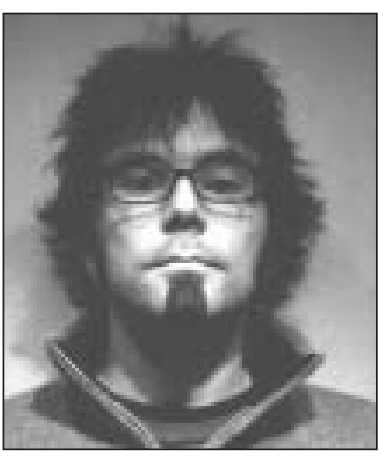

H.W. Harshaw

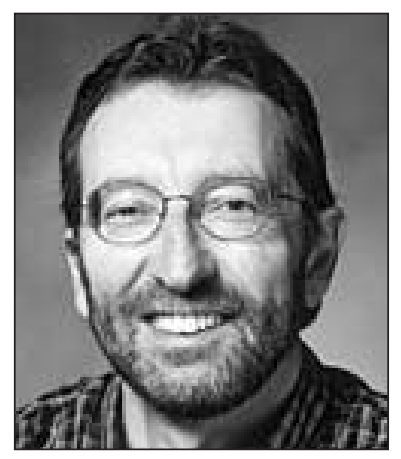

S.R.J. Sheppard

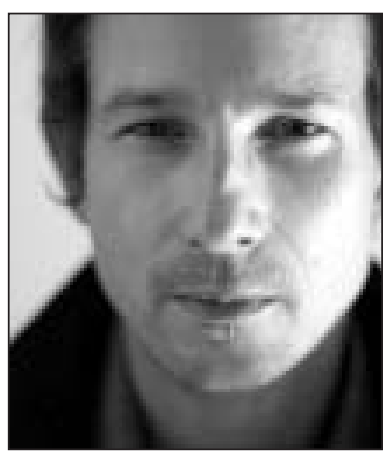

R.A. Kozak

between outdoor recreation and forestry in Canada, and (2) better serve the public in general, and the communities within which forestry operates more specifically. As Beckley et al. (2002) note, "[i]t is generally understood that one must be able to measure a phenomenon in order to manage it."

The management of publicly-owned forests in Canada has traditionally focused on timber production and economic outputs, and land-use decision-making processes

\section{Introduction}

Several years ago, D'Eon (2002) identified the need for forest managers in Canada to become willing partners in the collection of ecological data. This need was driven, in part, by increased opportunities for cooperative interdisciplinary research involving the forest industry, and by the identification of knowledge gaps in landscape-level ecology. Within the contexts of multidisciplinary research opportunities and gaps in knowledge, this paper makes a similar case for outdoor recreation: we urge forest managers to become active participants and supporters of the collection of empirical recreation data in order to (1) better understand the relationships have arguably been dominated by commercial and political interests (Mascarenhas and Scarce 2004, Harshaw et al. 2006). However, there has been a shift in forest management priorities toward the management of multiple values and a growing recognition of the important role of non-timber amenities, such as outdoor recreation values, in the sustainable forest management paradigm (Prins et al. 1990, Kimmins 1991, Carrow 1994, Robinson et al. 2001). This shift has also been recognized by the forest industry (e.g., Weyerhauser 1998) and the forest research community (e.g., Seeley et al. 2004). The consideration of outdoor recreation as an amenity value

\footnotetext{
${ }^{1}$ Collaborative for Advanced Landscape Planning (CALP), Department of Forest Resources Management, 2424 Main Mall, University of British Columbia, Vancouver, British Columbia, V6T $1 Z 4$.

${ }^{2}$ Author to whom correspondence should be sent. E-mail: harshaw@interchange.ubc.ca

${ }^{3}$ Department of Wood Science, 2424 Main Mall, Vancouver, British Columbia V6T 1 Z4.
} 
of forests, and its explicit incorporation into forest land-use management and planning, is important and in the public interest, as recreation appeals to a broad range of people and encompasses a range of activities and opportunities (Cordell et al. 1997, Federal-Provincial-Territorial Task Force on the Importance of Nature to Canadians 1999, Manning 1999). For many people, outdoor recreation provides one of the main opportunities to experience, interact with, and learn about forested landscapes; Bryan (2000) has characterized recreation activities as windows to the environment. Explicitly addressing recreation in land-use planning can help to alleviate uncertainties in forest planning and management by reducing conflict on the landbase, improving the quality of life of the public, and contributing to the social license of forestry activities.

The ubiquitous nature of recreation participation, the diversity of recreation participants, and the pervasiveness of recreation opportunities across the landscape has made outdoor recreation an explicit concern for landscape managers and planners (e.g., in forest certification), and has contributed to the recognition of the contribution that non-timber amenities make to civic society. Recreationists, as a stakeholder group, are distinct due to their diverse membership (Rollins and Robinson 2002). The Recreationist Stakeholder Group is really an amalgamation of many diverse groups that may have little in common except their pursuit of recreation activities during leisure time. As such, recreation stakeholders present challenges to traditional conceptions of land-use planning as they cut across strata of society in a way that many other stakeholder groups do not. However, recreation stakeholders are typically lumped together in land-use planning into two broad groups: motorized activities and nonmotorized activities; this grouping may mask certain key commonalities shared by these two groups, as well as differences among the activities and the recreationists that comprise them. Recreationists, both as members of civic society and as a recognized stakeholder group in forest land-use planning, have a legitimate need for involvement in land-use planning along with other stakeholders.

Many of the challenges faced by forest managers seeking to provide recreation experiences, and the land-use planners who seek to incorporate recreation values into the broader landscape matrix, are management issues. Outdoor recreation management is primarily concerned with people management: the management of their expectations and the management of the impacts that recreation participants have on one another and on the landscapes in which they pursue their activities. In this respect, outdoor recreation management is a social endeavour that attempts to balance the needs and desires of recreationists with the capacities of the natural environment on which they depend, as well as with other recreationists and other land uses (Harshaw 2005). One of the guiding principles of outdoor recreation management has been to provide high-quality experiences to recreationists, which have typically been measured in terms of visitor satisfaction (Manning 1999). Visitor satisfaction is a multidimensional concept, dependent upon resource, social, and management settings; it is also a subjective concept that is informed by the socioeconomic characteristics, cultural characteristics, experience, attitudes and preferences, and norms of the recreationists. Understanding recreationists' satisfaction with land-use planning outcomes for recreation opportunities is important for managers to assess their success in meeting land-use objectives.

The management of outdoor recreation would be complicated in its own right if forest managers and planners were only concerned with outdoor recreation issues, such as activity conflicts, visitor crowding, or infrastructure maintenance. However, outdoor recreation management does not occur in a vacuum; Crown lands that are designated for multiple-use should be managed for many public values (e.g., outdoor recreation, conservation, and resource extraction) that are distributed across the landscape. On these Crown lands, public values must be considered and balanced across the landbase, not segregated into distinct areas. Traditionally, the management focus of these lands has been on resource extraction and development, particularly in forestry, although this has been changing in recent years as a result of a reduction in forestry's dominance of GDP, an increased public awareness of environmental issues and concerns across the land base (not just within parks), as well as a shift in social values from a primarily utilitarian outlook to perspectives that are influenced by biocentric attitudes (e.g., Tarrant and Cordell 2002, McFarlane et al. 2006).

Land use and natural resource decisions involve the distribution of scarce resources; Smith and McDonough (2001) note that the issues that frame these decisions "often involve limited resources, but multiple constituencies, creating a situation in which it is impossible for everyone to get what they desire." Land-use planning processes that incorporate, and are responsive to, the full range of social values (e.g., industrial, commercial, community, and recreation interests) are vital for the sustainable management of forested landscapes (Canadian Council of Forest Ministers 2003). In a review of national studies of Canadian attitudes towards forest values and management, Robinson et al. (2001) conclude that nonmarket societal values have not been represented in forest policy, perhaps due to inadequate representation of forest stakeholders. In sum, recreation data needs are being driven by the depth and breadth of recreation use and through increased opportunities for public participation, the latter of which has served to bring many forest landscape issues to the public's attention.

We discuss four considerations for explicitly addressing outdoor recreation interests in forest land-use planning and for the collection of outdoor recreation data: (1) normative considerations, (2) pragmatic considerations, (3) economic considerations, and (4) governance. Alone, each of these considerations suggest important directions for forest managers and decision-makers; taken together, these considerations make a compelling case for explicitly collecting data about outdoor recreation resources and soliciting information about recreationists' behaviours, characteristics, and preferences. Gaps in knowledge are identified for each consideration. Approaches to outdoor recreation data collection area also discussed to provide an indication of the choices available to forest managers and planners.

\section{Normative Considerations}

Outdoor recreation provides and encourages many benefits to individual participants, society, the economy, and the environment (Manning 1999, Rollins and Robinson 2002). 
Ensuring that forest management addresses and recognizes these benefits may be considered a matter of equity. As the majority of Canadians participate in outdoor recreation activities (discussed below), it is important that opportunities for, and access to, a diversity of recreation opportunities be available and accounted for in forest land-use planning outcomes. However, as Rollins and Robinson (2002) note, a consequence of the diversity of outdoor recreation activities that are available, and of the differing motivations that people hold for participating in these activities, is that there is not an average outdoor recreation participant upon whom management may focus; the management of outdoor recreation means managing for diversity. In addition to being diverse, participation in outdoor recreation is dynamic-recreation participation changes in response to fluctuations in population characteristics (e.g., age, mobility), in the activity choices available to people (i.e., as new activities emerge and the popularity of existing activities may wane), and in access to recreation opportunities. Providing a diversity of outdoor recreation opportunities and settings across the landscape permits forest land-use planning to be responsive to changes in demand for outdoor recreation experiences over time (Clark and Stankey 1979). This future option for recreation opportunities provides for intergenerational equity, a cornerstone of most definitions of sustainability (e.g., Canadian Forest Service 2004). The Canadian Council of Forest Ministers (2003) has stated that the distribution of recreation is an important aspect of social equity. Karlis (2004) has argued that, in a social welfare state, such as Canada, recreation can be considered a fundamental right and entitlement as it is an important social need or requirement. Access to recreation is important for the social welfare of Canadians, and is an important avenue for the functioning of society. This argument finds support in the Sao Paulo Declaration (Fifth World Leisure and Recreation Association World Congress 1998) and the World Leisure Charter for Leisure (World Leisure Board of Directors 2000), which both detail the right of global citizens to leisure within the context of the Universal Declaration of Human Rights (United Nations General Assembly 1948). By understanding who recreationists are, forest planners and managers can better address their needs and concerns. For example, how do preferences for forest settings differ between recreation activity groups? What forest recreation activities are popular among recreationists? Who are the people that participate in recreation in forested landscapes (i.e., are they local residents or tourists; are they old or young; are they men or women)?

\section{Pragmatic Considerations}

Responsible forest stewardship and sustainability requires an understanding of the full spectrum of resource uses and activities across the landscape so that the impacts and contributions of these activities can be gauged and addressed. The pervasiveness of recreation participation in Canada and the potential for wide-ranging conflicts and impacts requires that outdoor recreation activities be explicitly addressed in forest land-use planning and management activities. The Importance of Nature to Canadians Survey (the Nature Survey) documented Canadian participation in naturerelated activities for 1996 (this survey has since been discontinued). In that year, $84.6 \%$ of Canadians aged 15 and older
Table 1. Canadian recreation participation for selected activities (Federal-Provincial-Territorial Task Force on the Importance of Nature to Canadians 1999).

\begin{tabular}{ll} 
Activity & Participation (\%) \\
\hline Camping & 18.8 \\
Hiking/Backpacking & 18.5 \\
Recreational fishing & 17.7 \\
Snowmobiling & 2.5 \\
Wildlife viewing & 18.6
\end{tabular}

Adapted from Federal-Provincial-Territorial Task Force on the Importance of Nature to Canadians (1999).

participated in one or more nature-related activities; of these, $43.7 \%$ engaged in outdoor recreation activities in natural areas, including parks and protected areas (there is the potential that participation in these activities may increase by $50 \%$ based on respondents' expressions of interest in participating in activities in natural areas). Table 1 summarizes some of the recreation activities that Canadians participated in. Williamson et al. (2002) examined the Nature Survey data in the context of forested eco-provinces and concluded that of the 225 million total user-days reported by Canadians for outdoor nature-based activities in 1996, 126.75 million userdays $(56.3 \%)$ occurred in forested ecosystems outside of parks and protected areas.

Coordinating the recreational activities of this large number of Canadians with other commercial and non-commercial forest-based activities on finite landscapes requires careful planning and management to avoid conflicts (i.e., among recreationists, and between recreation and forestry activities) and to minimize impacts from outdoor recreation on forestry (e.g., trampling of plantations) and vice versa.

The relationship between outdoor recreation and forestry is another pragmatic consideration that needs to be taken into account in land-use planning and management. This relationship is complex. Conflicts arise between desired landscape conditions as outdoor recreation and forestry compete for the same forest resources. Safety is also an issue for both groups. Yet, forestry activities are responsible for providing much of the access to recreation opportunities via road networks, which can also be a source of conflict as different recreation activities require different degrees of access (Clark and Stankey 1979). In their examination of the desirability of recreating in logged settings, Hunt et al. (2000) determined that demand (i.e., desirability) for recreating in logged settings was associated with socio-demographic characteristics (e.g., age, employment sector, education) and activity choice (e.g., consumptive or non-consumptive, motorized or nonmotorized); the authors suggest that the degree of timber harvesting in an area will influence the type and amount of recreation activity, and may limit the development of recreation (and nature-based tourism) opportunities. Balancing these different landscape uses in a public arena is a difficult task and one that requires careful planning. What is the relationship between forestry activities and outdoor recreation opportunities and experiences? In order to begin to address questions such as these, we need to better understand who recreation- 
ists are, how many recreationists there are, and what their motivations, preferences, and behaviours are. However, the demise of the Nature Survey after 1996 has created a gap in our knowledge of recreation trends. Has outdoor recreation participation increased as predicted? How has it changed?

\section{Economic Considerations}

There has been some difficulty accounting for the economic value of non-commercial outdoor recreation as it has not typically been a market-traded good or service. Restated, Canada's "natural wealth... is not fully reflected in commercial markets or adequately quantified in terms comparable with produced assets" (Federal-Provincial-Territorial Task Force on the Importance of Nature to Canadians 2000). In an effort to address this, the Nature Survey sought to quantify the economic value of Canadian participation in nature-related activities for 1996 (Federal-Provincial-Territorial Task Force on the Importance of Nature to Canadians 2000). Table 2 lists some of the indirect economic benefits provided by naturebased recreation to the Canadian economy in 1996.

This study also determined that Canadians spent $\$ 11$ billion in 1996 on all expenditures related to nature-related activities $^{4}$; an additional $\$ 2$ billion can be accounted for in unpaid enjoyment (e.g., option values). Direct recreationrelated expenditures of Canadians varied by activity; for example, Canadians participating in wildlife viewing spent $\$ 1.3$ billion in 1996, while recreational fishers spent $\$ 1.9$ billion and hunters spent $\$ 800$ million. Indirect economic benefits and impacts of nature-related outdoor recreation activities have also contributed to a number of national and provincial economic indicators, including tax revenues, individual income levels, and jobs. The indirect economic benefits and impacts also vary by recreation activity, suggesting that forest land-use planning that addresses a range of outdoor recreation opportunities may be able to better capture a diverse economic base. Taken together, these benefits may play an important role in the diversification of the Canadian economy, and thereby serve to increase the resilience of forest-dependent communities to forest sector fluctuations resulting from market changes, as well as other external drivers such as climate change.

These economic contributions do not account for other benefits of nature-related activities that may have indirect economic effects, such as faster recovery from stress (Ulrich $e t$ al. 1991), reduction of anxiety, and shorter recovery periods from surgeries (Ulrich 1993). Clearly, outdoor recreation has made contributions to the Canadian economy. Forest landuse planning and management that explicitly addresses outdoor recreation and seeks land-use solutions that permit and encourage recreation opportunities can help in the realization of these economic benefits 5 . However, we need to better understand recreation spending-how does recreation spending change over time and can recreation spending play

\footnotetext{
${ }^{4}$ This includes all costs associated with recreation participation: transportation, accommodation, food, equipment, supplies, licenses, entry fees, membership fees, and donations.

${ }^{5}$ In fact, the there is evidence to suggest that the USDA Forest Service has recognized this issue, as it has adopted a management philosophy that is less commodity-based, and more reflective of multiple values (Tarrant and Cordell 2002).
}

Table 2. Indirect contributions of outdoor recreation to the Canadian economy (1996).

\begin{tabular}{ll}
\hline Indirect Benefit & $\begin{array}{l}\text { Contribution } \\
\text { to Canada's Economy }\end{array}$ \\
\hline $\begin{array}{l}\text { Gross Business Production } \\
\text { Gross Domestic Product }\end{array}$ & $\$ 16.3$ billion \\
$\begin{array}{l}\text { Government Revenue from Taxes } \\
\text { Personal income }\end{array}$ & $\begin{array}{l}\$ 11.4 \text { billion } \\
\text { Number of jobs sustained }\end{array}$ \\
\hline
\end{tabular}

Adapted from Federal-Provincial-Territorial Task Force on the Importance of Nature to Canadians (2000).

a reliable role in diversifying the economic base of forestdependent communities? Further, there is a need to better understand the non-market values and benefits associated with recreation (e.g., increases in productivity, well-being, health, longevity, existence and vicarious values) and distinguish these values and benefits from traditional market values.

\section{Governance Considerations}

Governance considerations are concerned with the legislative, policy, and sustainable forest management certification aspects of forest management practices. The legislative framework that regulates forest management in Canada is informed by agreements at provincial, national, and international levels. The Working Group on Criteria and Indicators for the Conservation and Sustainable Management of Temperate and Boreal Forests (i.e., the Montreal Process) was formed in 1994 to develop national-level sustainable forest management criteria and indicators which were subsequently presented in 1995 as the Santiago Declaration. The development of these criteria and indicators was broadly seen as a step toward implementing Agenda 21 and the Statement of Forest Principles that were adopted by the UN Conference on Environment and Development in Rio de Janeiro in 1992. These criteria and indicators, though not legally binding, recognize the role of forests in providing long-term well-being of local populations, national economies, and the biosphere. The provision of opportunities for outdoor recreation was among the criteria and indicators that were developed (Montreal Process Working Group 1999).

The Canadian Council of Forest Ministers (CCFM) has developed a set of criteria and indicators for the sustainable management of forests that are consistent with the Montreal Process. Outdoor recreation is addressed under the criterion for economic and social benefits and is recognized as a significant non-commercial benefit that is highly valued by Canadians. Although the criterion and supporting elements are couched in economic terms, and recreation is no longer an explicit indicator as it was in previous iterations (due in part to the loss of data from the Nature Survey being discontinued), the CCFM does recognize that the long-term management of social benefits like recreation is required for sustainable forest management (CCFM 2003).

The sustainable forestry certification movement has emerged to be an important player in forest land-use planning in Canada, due in part to its market influence. Two certification mechanisms that have been particularly influential 
in Canada are the Canadian Standards Association (CSA) and the Forest Stewardship Council (FSC). The CSA certification standards were developed in collaboration with the CCFM and are explicitly linked to the CCFM criteria and indicators (the CCFM sustainable forest management criteria have been adopted virtually verbatim by CSA); as a result, the CSA framework is dynamic (as is CCFM's) and can incorporate new knowledge to reflect changing societal values. The FSC is an environmentally oriented organization that has adopted regionally developed standards for sustainable forest management; however, it has not yet been as widely adopted.

The CSA incorporates outdoor recreation into its vision of sustainable forest management under its Timber and NonTimber Benefits element. This element advocates for the management of a mix of both timber and non-timber benefits as a necessary component of sustainable forest management. Outdoor recreation is included as a non-timber benefit and is framed as an economic amenity (Canadian Standards Association 2002). Outdoor recreation is a consideration in three of the FSC principles for sustainable forest management and includes: access management and providing remote areas for recreation; explicitly addressing recreation in management objectives, strategies, and performance indicators and inventorying recreation resources; and the monitoring of impacts to recreation opportunities as both a cultural value and resource (Forest Stewardship Council Canada Working Group 2004). These frameworks suggest areas where recreation data are required, such as access management (i.e., which forest roads are being used most heavily). Having upto-date recreation inventories of available (and potential) recreation opportunities and recreation participation can serve to inform (and meet) certification requirements. Currently, the governance mechanisms discussed here primarily address inventory-related indicators (i.e., infrastructure, resources); however, there is a need for indicators to address experiential aspects of recreation, for it is the experiences that mean most to recreationists. How satisfied are recreationists with the recreation opportunities available to them? Similarly, are recreationists satisfied with the experiences they have had on Crown lands? Incorporating experiential indicators into forest management considerations should provide for a more holistic representation of outdoor recreation amenities. Outdoor recreation, due to the large proportion of Canadians that participate in activities, is one area where "elusive" social values or amenities may be addressed. Frameworks for incorporating recreation data already exist (e.g., inventories, survey approaches) that may only need to be updated or reactivated. These are discussed next.

\section{Approaches for Outdoor Recreation Data Collection}

There are two broad approaches to collecting (and managing) outdoor recreation data: surveys of use and inventories of resources (i.e., infrastructure such as trails, camp sites, and more broadly, opportunities). Surveys are excellent vehicles for examining outdoor recreationists' characteristics, behaviours, and preferences; one of the distinctions of human dimensions research is that we can ask people about whatever it is we would like to know instead of having to infer responses from observed behaviour. However, this does not diminish the need for, and benefits of, collecting and analyzing observed behaviour (i.e., revealed preferences). Inven- tories, on the other hand, are useful for cataloguing outdoor recreation resources; these inventories can be geospatially referenced, which increases their utility for planning and management activities (Harshaw and Meitner 2005). These two approaches are discussed below.

\section{Inventories}

Inventories are primarily descriptive tools that can provide an accounting of infrastructure (e.g., recreation resources and opportunities). Where geospatial recreation inventories exist, outdoor recreation values and amenities can be included in timber supply analyses and modeling; these inventories can also be used to engage local recreation stakeholders through hard copy and interactive maps. For example, in BC, the former Ministry of Forests (BCMoF; now the Ministry of Forests and Range) had developed a series of standards and procedures for cataloguing and monitoring recreation resources through the use of three distinct inventories: the Recreation Opportunity Spectrum (ROS), the Recreation Features Inventory, and the Recreation Facilities Inventory. Each of these inventories have been used in forest land-use planning and in forest-operations planning to provide information about the recreation resources and amenities that are present in the planning area. In BC, the Recreation Features Inventory is used to provide information about existing and potential recreation resources for timber supply review and to aid in the determination of annual allowable cut. This inventory contains information about the location, significance, and sensitivity of recreation resources (BCMoF 1998a). The Recreation Facilities Inventory identifies, both spatially and in an attribute database, the location, status, characteristics, and structures that are associated with forest recreation campgrounds, trails, and interpretive sites. The ROS was created so that the diverse range of outdoor recreation opportunity settings could be identified and assessed according to a standard set of principles and definitions. In $\mathrm{BC}$, the ROS is employed to catalogue areas of the province according to their current states of remoteness, naturalness, and expected social experience, and to provide land-use planners and resource managers with information about existing outdoor recreation opportunities and settings. The information can be used to incorporate recreation opportunities into timber supply reviews, and can also assist in the development of recreation guidelines in Higher Level Plans and forest district level recreation planning (BCMoF 1998b). Information that is derived from ROS analysis is applicable for most landscape planning exercises (Nilsen and Tayler 1997); it can be used to estimate the effects of management decisions, and may be applied to integrate outdoor recreation supply and demand information into other outdoor recreation management frameworks. The basic assumption of the ROS is that outdoor recreation quality can be secured through the identification and provision of a diverse set of recreation opportunities.

Other methods of inventorying outdoor recreation use include trail counters and user permits; these approaches are not as expensive as surveys and can provide useful contextual information. Trail and traffic counters provide an indication of recreation use, especially if their use is coordinated with on-site observation of recreation behaviour. Similarly, recreation permits and licences can be an excellent source of information (e.g., number of participants, place of residence, time 
and season of use); however, resource managers should be aware of some of the privacy concerns associated with these data sources.

\section{Survey approaches}

Whereas inventories provide information about the resources that are available, they do not provide an indication of whether recreationists' desired experiences have been metare recreationists satisfied with the experiences and opportunities that are available to them? This sort of question can be addressed through social science tools such as surveys. Surveys of recreation use can be deployed on their own if there are sufficient needs, or if there is a particular issue that needs to be informed by specific information. Alternatively, questions about outdoor recreation can be included in broader surveys of public opinion and preferences for forest management activities. The choice of how to construct the survey will depend on the scope of the issue at hand (e.g., strategic planning or site management) and on the resources that are available. The mode of survey delivery is another consideration for collecting data on recreation use, as there are several methods of soliciting the public.

A general mail survey is well suited for questionnaires that are of reasonable length, as respondents can take their time to complete the questions. Mail surveys can provide a sense of privacy to respondents, as it is a relatively anonymous vehicle for providing information (Salant and Dillman 1994). Mail surveys are useful for asking a large number of questions as respondents can choose when to complete the questionnaire, and do so when it is convenient to them. Mail surveys are also good for posing questions that may be complicated (i.e., those questions that require recall of events in the past, or questions that require mathematical skills such as estimating total recreation expenditures over one year). As with other approaches for survey delivery, the overall accuracy is dependent on the reliability of a mailing list (Salant and Dillman 1994). For a generalized provincial survey, it is difficult to get valid mailing addresses for all residents. In particular, it is difficult to get valid mailing addresses for rural residents and communities that have their mail delivered by post office box; this can result in a sample bias. An approach to address this concern is to recruit the sample by telephone and ask potential respondents to provide their mailing address.

Conducting surveys by telephone is a fairly straightforward approach to soliciting public opinion. Telephone surveys work well for short surveys (i.e., if the total time to complete the survey can be limited to 10 to 15 minutes) that do not require complex tasks (Salant and Dillman 1994). A benefit of this approach is that the data can be available relatively quickly, as there is no delay associated with gathering responses. Response rates from telephone surveys can be low ( $2 \%$ to $25 \%)$, in part due to the prevalence of telemarketing. However, if respondents can be assured early in the telephone solicitation that the survey is not for market-based research and is being conducted by an "independent" organization (such as a university), it is more likely that the response rate will be at the higher end of the expected completion rate.

The administration of surveys over the Internet has increased over the years, primarily due to the ease and relatively low cost of delivering the survey. A major limitation to sole reliance on the Internet as a means of administering surveys is that adequate lists of e-mail addresses do not exist; a further limitation is that not everyone has either access to a computer or to e-mail, which could introduce bias to the results. Access to the Internet is not universal; one estimate suggests that $61 \%$ of Canadian households have an Internet connection, and that $68 \%$ of Canadians' used the Internet for personal (i.e., non-business) reasons in 2005; however, the percentage of rural Canadians that used the Internet for personal reasons was 58\% (Statistics Canada 2006). One means of avoiding the limitations associated with sole reliance on the Internet as a means of survey delivery is to recruit potential respondents by telephone; potential respondents would be asked whether they would prefer to complete a mail survey or a web-based survey, and the appropriate questionnaire would be sent. A benefit of this approach is that it provides potential respondents with choice, which may help to induce response as sample members played a role in selecting mode of delivery. Potential respondents that do select the Internet-based survey should be assigned a unique identification number that serves to avoid self-selection, and permits sample error to be estimated (Dillman 2000); this limits the potential sample to those that have been randomly selected to participate, and precludes individuals repeatedly completing the questionnaire to produce a desired result.

The use of qualitative methods for collecting recreation data is another means of soliciting people's recreation behaviours, preferences, and attitudes. Qualitative methods include personal interviews, focus groups, and participant observation. Qualitative methods are excellent for gathering detailed information and can result in richer data sets that maintain the context of the meanings that respondents intend; however, data aggregation and comparison are more difficult with qualitative approaches than for quantitative approaches.

As surveys and inventories collect different kinds of data, and can answer different kinds of questions, they are complementary tools that can be employed to inform the management of outdoor recreation and help to facilitate the incorporation of outdoor recreation into forest management. Standards, procedures, and precedents currently exist for collecting and managing outdoor recreation data; broadly communicating these standards and procedures is necessary so that forest managers and planners can select the approach (or more likely, approaches) that are best suited to their needs, and understand the underlying methods that social scientists employ. The management of forested landscapes involves multiple partners (e.g., forest licensees, government agencies and ministries, academic researchers, and consultants); fostering an understanding of the need for, and approaches to, collecting and managing outdoor recreation data is essential to developing a commitment to better incorporating outdoor recreation in to forest management and planning.

\section{Conclusion}

As outdoor recreationists are not the sole users of forest resources, their needs and interests must be coordinated with other stakeholders. Outdoor recreation participation in Canada is fairly ubiquitous, given that $84.6 \%$ of Canadians participated in nature-related activities in 1996; the satisfaction of this stakeholder group ought, therefore, to be an important consideration among forest land-use managers and planners. However, as demonstrated in the preceding discussion, forest land-use planning is not a simple exercise. Although the arguments for incorporating outdoor recre- 
ation into forest management in Canada are established, there has been some difficulty in maintaining the links between outdoor recreation and forest management, in part due to data gaps. A consequence of this is that outdoor recreation stakeholder satisfaction with forest land-use planning outcomes is not well understood, which is problematic as outdoor recreation provides the primary means for public interaction with, and understanding of, forests.

The gaps in our knowledge of outdoor recreation are twofold. In the past, outdoor recreation data were collected, inventoried, and monitored as a part of regular forest management activities. However, recreation resource inventory data are incomplete, both in a temporal sense and in a spatial sense, as not all jurisdictions have collected this information and many of the existing inventories are out of date. Secondly, data on recreation participation and satisfaction have not been collected in a comprehensive or coordinated fashion. The Importance of Nature to Canadians Survey was an excellent vehicle for collecting data about recreation participation and expenditures at a national scale; reviving this useful data source would serve as an initial step to incorporating outdoor recreation into sustainable forest management, as it could directly inform the social and economic benefits that are measured in the CCFM, CSA, and FSC criteria and indicator frameworks.

Additionally, a strong research effort is required to define good indicators of recreation use. For example, frequency of outdoor recreation participation (by activity) can serve as both an indicator of recreation participation and of recreation pressure on biological resources and ecosystems. Measures contributing to this indicator could include the number of days spent and the number of trips taken to pursue an activity (Federal-Provincial-Territorial Task Force on the Importance of Nature to Canadians 1999, Williamson et al. 2002). In terms of measuring the recreation experience, initial data collection efforts should focus on attempting to understand and frame recreationists' satisfaction with their recreation experiences. Recreation satisfaction is a multidimensional concept that considers resource, social and management settings; documenting, understanding, and monitoring recreationists' satisfaction with land-use planning outcomes is important for managers to assess their success in meeting land-use objectives.

Economic and market concerns have influenced the manner in which public participation has been incorporated into commercial forest management. As forestry companies have sought certification to demonstrate their management and operations are ecologically, socially, and economically sustainable, they have formalized the role that the public, including recreation stakeholders, has in forest land-use planning primarily through the creation of public advisory committees. This has been an important step; however, this needs to be complemented and supported with information about stakeholder concerns and uses of forest lands.

There are compelling normative, pragmatic, economic, and governance reasons for deriving a deeper understanding of outdoor recreation in the practice of forestry. Understanding recreationists' satisfaction with land-use planning outcomes for recreation opportunities is important for managers to assess their success in meeting land-use objectives and, in the context of sustainable forest management, realiz- ing continual improvement. The availability of empirical outdoor recreation data can help forest managers to increase the certainty of their decisions as they become more aware of potential conflicts. By collecting and analyzing recreation data, researchers, practitioners, planners, and managers can better serve the recreating Canadian public, and begin to address the relationships between recreation and forestry in Canada, and perhaps even abroad.

\section{References}

Beckley, T., J. Parkins and R. Stedman. 2002. Indicators of forestdependent community sustainability: The evolution of research. For. Chron. 78(5): 626-636.

British Columbia Ministry of Forests (BCMoF) Forest Practices Branch. 1998a. Recreation Features Inventory: Procedures and standards manual. Resources Inventory Committee, Victoria, BC. 73 p.

British Columbia Ministry of Forests (BCMoF) Forest Practices Branch. 1998b. Recreation Opportunity Spectrum: Procedures and standards manual. Resources Inventory Committee, Victoria, BC. 29 p. Bryan, H. 2000. Recreation specialization revisited. Journal of Leisure Research 32(1): 18-21.

Canadian Council of Forest Ministers. 2003. Defining Sustainable Forest Management in Canada: Criteria and indicators 2003. Natural Resources Canada, Canadian Forest Service, Ottawa. 22 p.

Canadian Forest Service. 2004. The State of Canada's Forests, 2003-2004. Natural Resources Canada, Canadian Forest Service, Ottawa. 93 p.

Canadian Standards Association. 2002. CAN/CSA-Z809-02 Sustainable Forest Management: Requirements and Guidance A National Standard of Canada (approved May 2003). Canadian Standards Association, Mississauga, ON. 51 p.

Carrow, R. 1994. Integrated resource management - A case study of unrealized potential. For. Chron. 70(1): 19-21.

Clark, R.N. and George H. Stankey. 1979. The Recreation Opportunity Spectrum: A Framework for Planning, Management, and Research. USDA Forest Service Pacific Northwest Forest and Range Experiment Station, Portland, OR. Gen. Tech. Rep. PNWGTR-98. 32 p.

Cordell, H.K., J. Teasley and G. Super. 1997. Outdoor recreation in the United States: Results from the National Survey on Recreation and the Environment (All Forest Service Regions). USDA Forest Service Outdoor Recreation and Wilderness Assessment Group, and the Department of Agriculture and Applied Economics, University of Georgia, Athens, GA. 209 p.

D'Eon, R.G. 2002. Forest fragmentation and forest management: A plea for empirical data. For. Chron. 78(5): 686-689.

Dillman, D.A. 2000. Mail and Internet Surveys: The Tailored Design Method (2nd ed.). John Wiley and Sons, Inc., Toronto.

Federal-Provincial-Territorial Task Force on the Importance of Nature to Canadians. 1999. The Importance of Nature to Canadians Survey Highlights. Environment Canada, Ottawa. Report No. EN47311/1999E. 55 p.

Federal-Provincial-Territorial Task Force on the Importance of Nature to Canadians. 2000. The Importance of Nature to Canadians: The economic significance of nature-related activities. Environment Canada, Ottawa. Report No. EN47-312/2000E. 49 p. Fifth World Leisure and Recreation Association World Congress. 1998. Sao Paulo Declaration: Leisure in a globalized society. World Leisure and Recreation Association, Sao Paulo, Brazil.

Forest Stewardship Council Canada Working Group. 2004. National Boreal Standard. Forest Stewardship Council (FSC) Canada Working Group, Toronto, ON. 181 p.

Harshaw, H.W. 2005. The Representation of Outdoor Recreation in Land-Use Planning in British Columbia [Ph.D.]. University of British Columbia, Vancouver, BC. 318 p. 
Harshaw, H.W., R.A. Kozak and S.R.J. Sheppard. 2006. How well are outdoor recreationists represented in forest land-use planning? Perceptions of recreationists in the Sea-to-Sky Corridor of BC. Landscape and Urban Planning. 78(1-2): 33-49.

Harshaw, H.W. and M.J. Meitner. 2005. Chapter 8: Recreation Management. In S. Watts (ed.). Forestry Handbook for British Columbia. 5th ed. pp. 274-305. Forestry Undergraduate Society, Faculty of Forestry, University of British Columbia, Vancouver, BC. Hunt, L., G.D. Twynam, W. Haider and D.W. Robinson. 2000. Examining the desirability for recreating in logged settings. Society and Natural Resources 13(8): 717-734.

Karlis, G. 2004. Leisure and Recreation in Canadian Society: An introduction. Thompson Educational Publishing, Inc., Toronto, ON. 307 p.

Kimmins, J.P. 1991. The future of the forested landscapes of Canada. For. Chron. 67(1): 14-18.

Manning, R.E. 1999. Studies in Outdoor Recreation: Search and research for satisfaction. Oregon State University Press, Corvallis, OR. 374 p.

Mascarenhas, M. and R. Scarce. 2004. "The intention was good": Legitimacy, consensus-based decision making, and the case of forest planning in British Columbia, Canada. Society and Natural Resources 17(1): 17-38.

McFarlane, B.L., R.C.G. Stumpf-Allen and D.O. Watson. 2006. Public perceptions of natural disturbance in Canada's national parks: The case of the mountain pine beetle (Dendroctonus ponderosae Hopkins). Biological Conservation 130(3): 340-348.

Montreal Process Working Group. 1999. The Montreal Process: Criteria and indicators for the conservation and sustainable management of temperate and boreal forests. Montreal Process Working Group (Montreal Processes Liaison Office, Canadian Forest Service, Natural Resources Canada, Ottawa). 19 p.

Nilsen, P. and G. Tayler. 1997. A comparative analysis of protected area planning and management frameworks. In S.F. McCool and D.N. Cole (comps.). Proceedings_-Limits of Acceptable Change and related planning processes: progress and future directions, 1997 May 20-22, Missoula, MT. Gen. Tech. Rep. INT-GTR-371. pp. 49-57. U.S. Department of Agriculture, Forest Service, Rocky Mountain Research Station, MT, Ogden, UT. Gen. Tech. Rep. INT-GTR-371.

Prins, R., W. Adamowicz and W. Phillips. 1990. Non-timber values and forest resources: An annotated bibliography. University of Alberta, Faculty of Agriculture and Forestry, Department of Rural Economy, Edmonton, AB. Project Report 90-03.
Robinson, D.W., M. Robson and R. Rollins. 2001. Towards increased citizen influence in Canadian forest management. Environments 29(2):21-41.

Rollins, R. and D.W. Robinson. 2002. Social science, conservation, and protected areas. In P. Dearden and R. Rollins (eds.). Parks and Protected Areas in Canada: Planning and Management. 2nd ed. pp. 117-147. Oxford University Press, Toronto, ON.

Salant, P. and D.A. Dillman. 1994. How to Conduct Your Own Survey. John Wiley and Sons Inc., New York.

Seely, B., J. Nelson, R. Wells, B. Peter, M. Meitner, A. Anderson, H. Harshaw, S. Sheppard, F. Bunnell, H. Kimmins and D. Harrison. 2004. The application of a hierarchical, decision-support system to evaluate multi-objective forest management strategies: A case study in northeastern British Columbia, Canada. Journal of Forest Ecology and Management 199: 283-305.

Smith P.D. and M.H. McDonough. 2001. Beyond public participation: Fairness in natural resource decision making. Society \& Natural Resources 14(3): 239-249.

Statistics Canada. 2006. Canadian Internet Use Survey: 2006. The Daily, Catalogue 11-001-XIE, 5-7 [online]. Available from http://www.statcan.ca/Daily/English/060815/d060815.pdf.

Tarrant, M.A. and H.K. Cordell. 2002. Amenity values of public and private forests: Examining the value-attitude relationship. Environmental Management 30(5): 692-703.

Ulrich, R.S. 1993. Biophilia, biophobia, and natural landscapes. In S.R. Kellert and E.O. Wilson (eds.). The Biophilia Hypothesis. pp. 73-137. Island Press, Washington, DC.

Ulrich, R.S., R. Simons, B.D. Losito, E. Fiorito, M.A. Miles and M.

Zelson. 1991. Stress recovery during exposure to natural and urban environments. Journal of Environmental Psychology 11(3): 201-230.

United Nations General Assembly. 1948. Universal Declaration of Human Rights.

Weyerhaeuser, G.H. 1998. The challenge of adaptive forest management: Aren't people part of the ecosystem too? For. Chron. 74(6): 865-870.

Williamson, T.B., R. Hoscheit and H. Luttrell. 2002. Participation in Outdoor Recreation in Forested Ecoprovinces in Canada in 1996. Natural Resources Canada, Canadian Forest Service, Northern Forestry Centre, Edmonton, AB. Information Report No. NOR-X385.

World Leisure Board of Directors. 2000. Charter for leisure. World Leisure and Recreation Association. 